\title{
Seizures and Epilepsy following Subarachnoid Hemorrhage: A Review on Incidence, Risk Factors, Outcome and Treatment
}

\section{Crises convulsivas e epilepsia após hemorragia subaracnoide: uma revisão sobre incidência, fatores de risco, desfecho e tratamento}

Miguel Bertelli Ramos ${ }^{1}$ Manoel Jacobsen Teixeira ${ }^{2}$ Eberval Gadelha Figueiredo ${ }^{2}$

1 School of Medicine, Universidade de Caxias do Sul, Caxias do Sul, RS, Brazil

${ }^{2}$ School of Medicine, Universidade de São Paulo, SP, Brazil

Address for correspondence Miguel Bertelli Ramos, Escola de Medicina, Universidade de Caxias do Sul, Caxias do Sul, RS, Brazil (e-mail: mbramos1@ucs.br).

Arq Bras Neurocir 2018;37:206-212.

\begin{abstract}
Keywords

- subarachnoid hemorrhage

- epilepsy

- incidence

- risk factors

- anticonvulsants

- prognosis
\end{abstract}

Resumo
The mortality rates of subarachnoid hemorrhage (SAH) average $51 \%$, and survivors frequently experience acute and long-term neurological conditions, including seizures and epilepsy. The incidence of post SAH-related seizures and epilepsy, its risk factors, outcomes and management are controversial. The present paper aims to discuss these aspects, to provide the pros and cons of different management options of this condition. A review on PubMed was performed encompassing the incidence of seizures and epilepsy following $\mathrm{SAH}$, the risk factors for its occurrence, its related outcomes, and treatment. The incidence of seizures and epilepsy following SAH varies widely in the literature (from 6 to $26 \%$ ). Some possible risk factors were identified, such as middle cerebral artery (MCA) aneurysm, Hunt and Hess grade III, aneurysm clipping, thick subarachnoid clot, intracerebral hemorrhage, rebleeding, ischemic brain infarction, Fisher grade III or IV, acute hydrocephalus, hypertension history and poor World Federation of Neurosurgical Societies (WFNS) grade. Nevertheless, these relations are frequently uncertain. Also, it appears that the outcome of patients who suffered SAH is worsened by seizures. Given these uncertainties, the need for antiepileptic drug (AED) prophylaxis, the choice of the best drug and dose, as well as the duration of the treatment are controversial topics. However, some recommendations based on low quality evidence are reasonable to be adopted. These include considering AED prophylaxis when a seizure occur after SAH, considering routine long-term AED prophylaxis in specific populations, considering electroencephalogram (EEG) monitoring, and avoiding phenytoin prescription. That is, an individualized approach appears to be the best option, since there is no high-quality evidence.

As taxas de mortalidade da hemorragia subaracnoide (HSA) são de $51 \%$, e os sobreviventes frequentemente sofrem condições neurológicas agudas e em longo prazo, incluindo convulsões e epilepsia. A incidência de convulsões e epilepsia após received June 6, 2018 accepted July 10,2018 ISSN 0103-5355.
Copyright $\odot 2018$ by Thieme Revinter Publicações Ltda, Rio de Janeiro, Brazil
License terms

c) $(1) \$$ 


\author{
Palavras-chave \\ - hemorragia \\ subaracnoidea \\ - epilepsia \\ - incidência \\ - fatores de risco \\ - anticonvulsivantes \\ - prognóstico
}

HSA, seus fatores de risco, desfecho e tratamento são controversos. O presente artigo pretende discutir esses aspectos para fornecer os prós e os contras de diferentes opções de manejo dessa condição. Realizou-se uma revisão no PubMed, englobando a incidência de convulsões e epilepsia após HSA, os fatores de risco para a sua ocorrência, seu desfecho e tratamento. A incidência de convulsões e epilepsia após HSA varia amplamente na literatura (de 6 a 26\%). Alguns possíveis fatores de risco foram identificados, como aneurisma da artéria cerebral média (ACM), Hunt e Hess grau III, clipagem do aneurisma, coágulo subaracnoide espesso, hemorragia intracerebral, ressangramento, isquemia cerebral, Fisher grau III ou IV, hidrocefalia aguda, história de hipertensão e uma pontuação desfavorável na escala da Federação Mundial de Sociedades de Neurocirurgia (WFNS, na sigla em inglês). Entretanto, essas relações frequentemente são incertas. Além disso, os pacientes que apresentam convulsões após HSA parecem ter pior desfecho. Devido a essas incertezas, a necessidade de profilaxia com anticonvulsivantes, a escolha do melhor fármaco e posologia, e a duração do tratamento são controversos. Contudo, algumas recomendações baseadas em evidências de baixa qualidade podem ser adotadas. Elas incluem considerar profilaxia com anticonvulsivantes para convulsões pós HSA, considerar profilaxia rotineira em longo prazo em populações específicas após HSA, considerar monitoramento com eletroencefalograma (EEG), e evitar a prescrição de fenitoína. Ou seja, uma abordagem individual parece a melhor opção até que haja evidências de alta qualidade.

\section{Introduction}

Mortality rates due to subarachnoid hemorrhage (SAH) seem to be decreasing in some countries; yet, it averages $51 \%{ }^{1-5}$ However, survivors often develop acute and long-term severe neurological conditions. These conditions include neurocognitive dysfunction, seizures and epilepsy, as well as various other focal neurological deficits. ${ }^{1,6,7}$

The incidence of seizures and further epilepsy development following SAH vary widely in literature. ${ }^{8-16}$ More recent data suggest that this figure is decreasing over the years, which may be explained by the recent improvement in SAH management. ${ }^{7,17-24}$ Although the exact incidence remains unclear, several factors were described to be associated with a greater risk of seizures and epilepsy development after $S A H .{ }^{7,10,17,25-29}$ Moreover, the outcomes appear to be worsened by seizures after SAH - with some controversies. $8,10,14,15,18,30$

Since there is a high variability regarding the incidence, the risk factors and outcome of seizures and epilepsy after $\mathrm{SAH}$, the need for antiepileptic drug (AED) prophylaxis, the choice of the best drug and dose, as well as the duration of the treatment remain unclear. Therefore, this paper aims to discuss aspects related to the incidence, risk factors, outcome, and treatment of seizures and epilepsy after SAH, to provide the pros and cons of different management options.

\section{Materials and Methods}

A literature review was performed on PubMed during the period of February 2018, encompassing aspects related to the incidence of seizures and epilepsy following SAH, the risk factors for their occurrence after SAH, the related outcomes, and the treatment of this condition.

\section{Key Concepts}

The International League Against Epilepsy (ILAE) provides 3 conditions in which epilepsy can be defined: 1 ) at least two unprovoked (or reflex) seizures occurring more than 24 hours apart; 2) one unprovoked (or reflex) seizure and a probability of further seizures similar to the general recurrence risk (at least $60 \%$ ) after 2 unprovoked seizures, occurring over the next 10 years; or 3 ) diagnosis of an epilepsy syndrome. ${ }^{31}$

A seizure is defined by a transient occurrence of signs and/ or symptoms due to abnormal excessive or synchronous neuronal activity in the brain. ${ }^{31}$ In addition, these seizures can be classified as provoked or unprovoked. Provoked seizures, also called 'reactive seizures' or 'acute symptomatic seizures,' are defined as seizures caused by an acute condition, including SAH. Conversely, unprovoked seizures are those of unknown etiology or those that occur in relation to an existing prior brain lesion or progressive nervous system disorder. ${ }^{31}$

A SAH can provoke seizures as well as cause a brain lesion that will then lead to unprovoked seizures. Therefore, it is possible for a patient who suffered SAH to develop late epilepsy (that is, epilepsy), with one of the criteria for epilepsy diagnosis occurring after one week of the onset of the acute event. ${ }^{10}$

\section{Incidence}

The incidence of seizures following SAH varies widely in the literature, reaching values between $6 \%$ and $26 \%{ }^{8-16}$ Although more recent studies show a decrease in the incidence of clinical seizures, the spreading of continuous electroencephalogram (EEG) monitoring allows the recognition of nonconvulsive status epilepticus (NCSE) as well as subclinical seizures. ${ }^{8-10,14-16}$ It is also important to state that 
the majority of studies was retrospective and there is the possibility that some seizures were not registered. ${ }^{28}$ In addition, partial seizures were sometimes excluded and, frequently, seizures are not witnessed by a health professional. ${ }^{7,10}$ The onset of seizure-like behavior was reported to be frequent, accounting for a big part of post SAH seizures. $8,10,32,33$ However, it is not known if these are truly epileptic in origin or if they represent just a posturing at the time of the aneurysmal rupture. ${ }^{32,33}$

The occurrence of seizures after the onset of $\mathrm{SAH}$ is, in general, less common than the onset seizures. ${ }^{29}$ Among posttreatment seizures, a systematic review demonstrated that early posttreatment events (those occurring during the initial hospital stay after intervention) were observed in $2.3 \%$ of patients who suffered $\mathrm{SAH}$, while late seizures (occurring after discharge from the hospital) were observed in 5.5\%, with an average latency of 7.45 months. ${ }^{28}$ In addition, Claassen et al ${ }^{18}$ showed that $11 \%$ of the patients who suffered SAH had at least one unprovoked seizure in one year as survivors. Yet, seizures may occur years after the initial SAH episode. ${ }^{34,35}$ Actually, late seizures can be related to rebleeding of the aneurysm, gliosis, and development of meningocerebral cicatrix. ${ }^{13,34}$

Since the conditions to make the diagnosis of epilepsy were updated in 2014, its precise incidence following SAH may be difficult to assess in older studies. ${ }^{31}$ Actually, the incidence of late epilepsy following SAH remains uncertain, ranging from 3 to $35 \% .^{7,17-24}$ However, it appears to be decreasing over the years, which may be explained by improvements in the management of SAH. ${ }^{36}$ For instance, Buczacki et al ${ }^{7}$ conducted a large retrospective study, in which only 23 (4.9\%) out of 472 patients developed late epilepsy after the clipping of ruptured aneurysms. Similarly, the international subarachnoid aneurism trial (ISAT) trial data showed that 25 (4\%) out of 612 patients developed late epilepsy after 12 months of follow-up. ${ }^{37}$

\section{Risk Factors}

Several factors were associated with a high risk of seizures and late epilepsy following SAH ( - Table 1)..$^{70,17,25-29}$ A systematic review of the literature showed that the occurrence of seizures was strongly related to aneurysm in the middle cerebral artery (MCA), Hunt and Hess $(\mathrm{HH})$ grade III and clipping microsurgical repair. ${ }^{29}$ Other reported risk factors include thick subarachnoid clot, intracerebral hemorrhage, rebleeding prior to operation, infarction, Fisher grade III or IV, poor World Federation of Neurosurgical Societies (WFNS) grade, acute hydrocephalus, and past medical history of hypertension. ${ }^{7,10,17,25-28}$ In addition, seizures at the onset of aneurysm rupture were related to increased epilepsy incidence, ${ }^{14,18}$ but this remains controversial. ${ }^{10}$ Moreover, acute symptomatic seizures have a lower risk for further unprovoked seizure than remote symptomatic seizures. ${ }^{38}$ A detailed discussion about each possible risk factor is provided subsequently.

\section{Aneurysm Location}

Raper et $\mathrm{al}^{29}$ performed a systematic review and found that, among patients who had seizures after $\mathrm{SAH}$, there was a strong relationship to its location in the MCA. Indeed, 39\% of them had
Table 1 List of possible risk factors for the development of seizures and epilepsy after subarachnoid hemorrhage

\begin{tabular}{|l|}
\hline - MCA aneurysm \\
\hline - Hunt and Hess grade III \\
\hline - Clipping microsurgical repair \\
\hline - Thick subarachnoid clot \\
\hline - Intracerebral hemorrhage \\
\hline - Rebleeding prior to operation \\
\hline - Infarction \\
\hline - Fisher grade III or IV \\
\hline - Acute hydrocephalus \\
\hline - History of hypertension \\
\hline - Poor WFNS grade \\
\hline - Onset seizure \\
\hline
\end{tabular}

Abbreviations: MCA, middle cerebral artery; WFNS, World Federation of Neurosurgical Societies.

an MCA aneurysm, compared with $29.3 \%$ in the anterior communicating artery, $13.8 \%$ in the internal carotid artery, $8.9 \%$ in the posterior communicating artery, $6.5 \%$ in the anterior cerebral artery, and $2.4 \%$ in the basilar apex locations.

\section{Clinical and Radiological Scales}

Clinical classifications, such as the HH and the WFNS scores, have been shown to be related to seizure occurrence after SAH. ${ }^{7,29}$ A great number (41.7\%) of seizure events was observed among patients with a $\mathrm{HH}$ grade III. Conversely, this figure was much lower for grades I (25\%), II (18.3\%), IV (11.7\%) and $\mathrm{V}(3.3 \%) .{ }^{29}$ In addition, a study reported that a poor WFNS grade (excluding grade 5 ) after SAH was related to an increased risk of late epilepsy development. ${ }^{7}$ In fact, this occurred in $1.4 \%$ of grade I patients, $3.8 \%$ of grade II, $9.6 \%$ of grade III, and $12.5 \%$ of grade IV. The Fisher radiological scale was also related to seizure incidence after SAH. ${ }^{10}$ Actually, worse grades (Fisher III and IV) had a stronger relationship with late epilepsy than better grades (Fisher I and II), with an odds ratio of 1.81 and confidence interval $(\mathrm{CI})$ between 1.07 and 2.15.

\section{Type of Treatment}

There is a very strong correlation between the type of treatment (such as surgical clipping or endovascular coiling) and the occurrence of further seizures. Raper et al, ${ }^{29}$ in their systematic review, showed that $18.4 \%$ of patients who had post SAH seizures underwent endovascular coiling of the aneurysm. Conversely, $81.6 \%$ underwent surgical clipping.

\section{Onset Seizures}

The presence of seizures at the onset of aneurysm rupture were related to increased epilepsy incidence, ${ }^{14}$ but this remains controversial. ${ }^{10}$ Butzkueven et $\mathrm{al}^{14}$ showed that onset seizures and late seizures within the first 6 weeks were independently related (odds ratio $[\mathrm{OR}]=27 ; p<0.01$ ). Conversely, onset seizures were not predictors of late epilepsy in the study of Choi et al. ${ }^{10}$ In addition, acute symptomatic seizures have a 
lower risk of further unprovoked seizure occurrence than remote symptomatic seizures. ${ }^{38}$

\section{Other Associated Comorbidities}

Various other associated comorbidities were described to be related to an increased seizure incidence following $\mathrm{SAH}$. These include history of hypertension, presence of a thick subarachnoid clot, intracerebral hemorrhage, rebleeding prior to operation, ischemic brain infarction, and acute hydrocephalus. ${ }^{17,25-28}$

\section{Outcome}

The impact of seizures after SAH on the outcome of the patient is not so clear, although they appear to be an independent risk factor to a poor outcome. ${ }^{14,18}$ Some evidence pointed that seizures following SAH are independent predictors of a poor prognosis. ${ }^{14}$ Indeed, Butzkueven et $\mathrm{al}^{14}$ showed that, besides the already mentioned increased risk for late epilepsy development, disability after weeks of the SAH episode (according to the Glasgow Outcome Scale) was independently related to the presence of onset seizure. Another study demonstrated that epilepsy after SAH was related to a poor functional recovery (using the modified Rankin Scale), to an increased instrumental disability (using the Lawton Instrumental Activities of Daily Living scale), to a reduced quality of life (using the Sickness Impact Profile), and to increased anxiety (using the Spielberger Anxiety Inventory). ${ }^{18}$ Moreover, NCSE was also strongly related to a poor outcome. ${ }^{15,30}$ Conversely, other studies found no differences in the outcomes of patients who suffered SAH and had a seizure. , $^{8,10}$

\section{Treatment}

Neither primary nor secondary prevention treatments are supported or refuted for seizures related to SAH, according to a 2013 Cochrane Review. ${ }^{39}$ This was explained by an absence of prospective randomized clinical trials or other high-quality studies encompassing this matter. Due to this lack, there is a lot of controversy regarding the need for AED prophylaxis, choice of the best drug and dose, as well as duration of the treatment. Indeed, the prophylactic use of AED after SAH varies dramatically (from 7 to 93\%) among physicians from different countries. $^{40}$

Some guidelines and recommendations for the management of SAH (including seizure management) were published recently. In 2011, the recommendations from the Multidisciplinary Consensus Conference of the Neurocritical Care Society (NCS) were published, ${ }^{33}$ whereas in 2012 the American Heart Association (AHA)/American Stroke Association (ASA) recommendations ${ }^{32}$ on this subject were published. None of these societies support or refute strongly one or another approach based on high-quality evidence regarding the treatment of seizures after $\mathrm{SAH}$, although some provided points are of important value for the clinical decision. - Table 2 shows the recommendations by both entities.

\section{When to Use Antiepileptic Drugs}

First of all, it is important to emphasize that there is no consensus regarding the benefits of primary and secondary prophylaxis with AEDs after SAH. ${ }^{39}$ Actually, there are even studies that showed a worse prognosis among patients who used AEDs after SAH, mainly phenytoin. ${ }^{41,42}$ Therefore, the choice to use or not to use remains more empirical than evidence-based. In the next paragraph, the separated treatment recommendations for primary and secondary seizure prevention related to SAH are provided.

\section{Primary Prevention}

As shown in - Table 2, both the NCS and the AHA/ASA agree regarding routine prophylaxis for seizures after $\mathrm{SAH}$.

Table 2 Management of seizures after SAH according to the Neurocritical Care Society recommendations and the AHA/ASA guideline

\begin{tabular}{|c|}
\hline Neurocritical Care Society recommendations $(2011)^{33}$ \\
\hline $\begin{array}{l}\text { - Routine use of anticonvulsant prophylaxis with phenytoin is not recommended after SAH (low-quality evidence-strong } \\
\text { recommendation) }\end{array}$ \\
\hline $\begin{array}{l}\text { - Routine use of other anticonvulsants for prophylaxis may be considered } \\
\text { (very low-quality evidence-weak recommendation). }\end{array}$ \\
\hline $\begin{array}{l}\text { - If anticonvulsant prophylaxis is used, a short course (3-7 days) is recommended } \\
\text { (low-quality evidence-weak recommendation). }\end{array}$ \\
\hline $\begin{array}{l}\text { - In patients who suffer a seizure after presentation, anticonvulsants should be continued for a duration defined by local practice } \\
\text { (low-quality evidence-weak recommendation). }\end{array}$ \\
\hline $\begin{array}{l}\text { - Continuous EEG monitoring should be considered in patients with poor-grade SAH who fail to improve or who have } \\
\text { neurological deterioration of undetermined etiology (low-quality evidence-strong recommendation). }\end{array}$ \\
\hline AHA/ASA guideline $(2012)^{32}$ \\
\hline $\begin{array}{l}\text { - The use of prophylactic anticonvulsants may be considered in the immediate posthemorrhagic period } \\
\text { (Class IIb; Level of Evidence B). }\end{array}$ \\
\hline $\begin{array}{l}\text { - The routine long-term use of anticonvulsants is not recommended (Class III; Level of Evidence B), but may be considered } \\
\text { for patients with known risk factors for delayed seizure disorder, such as prior seizure, intracerebral hematoma, intractable } \\
\text { hypertension, infarction, or aneurysm at the middle cerebral artery (Class IIb; Level of Evidence B). }\end{array}$ \\
\hline
\end{tabular}

Abbreviations: AHA, American Heart Association; ASA, American Stroke Association; EEG, electroencephalogram; SAH, subarachnoid hemorrhage. 
Indeed, their statements say that routine prophylaxis with AEDs may be considered right after SAH. Neither of the recommendations supports a long-term prophylaxis with AEDs. ${ }^{32,33}$ However, the AHA/ASA guideline states that this prophylaxis may be considered in some risk populations. ${ }^{32}$ These include those with intracerebral hemorrhage, intractable hypertension, infarction, or aneurysm at the MCA. It is also reported that, once the AED treatment is initiated, three days of prophylaxis should be preferred, since the percentages of early and late seizures were similar when compared with a long-term course of AEDs. ${ }^{43}$

\section{Secondary Prevention}

In patients who suffer a seizure after presentation, the NCS recommendations state that $A E D$ treatment should be continued, and the AHA/ASA guideline supports the consideration of AED treatment. ${ }^{32,33}$ Since there is an absence of poststroke absolute predictors for further epilepsy development, many physicians empirically treat seizures in the setting of a stroke history in the past 2 to 3 years. ${ }^{44}$ The American Academy of Neurology (AAN), together with the American Epilepsy Society (AES), made an evidence-based guideline for the management, in general, of first unprovoked seizures. ${ }^{45}$ These recommendations are shown in -Table 3.

For acute symptomatic seizures, the decision to start or not AED treatment depends on the severity of the underlying illness, the duration of the seizure, and the risks associated with a recurrent seizure. When the cause is severe SAH, therapy is generally initiated, since a seizure may worsen the prognosis of the patient. ${ }^{14,18}$ Thus, an individualized approach seems the most convenient.

Conversely, the literature strongly supports the initiation of AED treatment after the second unprovoked seizure. Indeed, Hauser et $\mathrm{al}^{46}$ showed that $73 \%$ of those with 2 or 3 unprovoked seizures had further seizures within 4 years, whereas the risk of a second unprovoked seizure after 5 years of the first seizure was 33\%.Given the high seizure incidence after the second seizure, AED treatment should be initiated after the second seizure. ${ }^{46,47}$

\section{The Antiepileptic Drug Choice}

No AED was reported clearly to be the most effective in a few randomized clinical trials in the literature, and the choice of a specific AED depends mainly on its pharmacokinetic properties, collateral effects, cost, tolerance, seizure type, and on the characteristics of the patient. ${ }^{48-52}$ As a general rule, newer AEDs are more tolerated than others - with some exceptions. ${ }^{48}$ In a single study, it was shown that phenytoin may worsen the neurological outcome in patents who suffered SAH. ${ }^{41}$ Due to this, the statement of the NCS recommends against the use of phenytoin for seizure prophylaxis in the setting of SAH. ${ }^{33}$ However, it is unclear if AEDs other than phenytoin have also a deleterious effect, so their prescription must be made with caution.

\section{Electroencephalogram Monitoring}

In poor-grade patients who suffered SAH, NCSE and subclinical seizures can be detected with EEG monitoring in many cases. Given that NCSE is strongly related to poor outcomes after $\mathrm{SAH},{ }^{24,37}$ it is reasonable to consider both EEG monitoring in poor-grade patients and AED treatment, although the literature lacks information regarding the efficacy of AED therapy in this setting. Indeed, there is a statement of the NCS recommending a specific approach in terms of continuous EEG monitoring (- Table 2). ${ }^{33}$

\section{Conclusion}

The lack of consensus in the literature regarding the incidence, risk factors, outcomes and treatment of SAH-related seizures and epilepsy makes difficult to the physician to determine the need for AED prophylaxis, the choice of the best drug and dose, as well as the duration of treatment. So far, recommendations are in general based on low quality evidence, but they suggest some relevant points, such as considering AED prophylaxis when a seizure occurs after $\mathrm{SAH}$, considering routine long-term AED prophylaxis in specific populations, considering continuous EEG monitoring, and avoiding phenytoin prescription. ${ }^{32,33}$ In other words, it is reasonable to individualize the approach for

Table 3 Recommendations from the 2015 AAN/AES guideline for the management of first unprovoked seizure in adults 45

- Adults presenting with an unprovoked first seizure should be informed that the chance of a recurrent seizure is greatest within the first 2 years after the first seizure (21-45\%) (Level A).

- Clinicians should also advise these patients that clinical factors associated with an increased risk of seizure recurrence include a prior brain insult such as stroke or trauma (Level A), an EEG with epileptiform abnormalities (Level A), a significant brain imaging abnormality (Level B), or a nocturnal seizure (Level B).

- Clinicians should advise patients that, although immediate AED therapy, as compared with delay of treatment pending a second seizure, is likely to reduce the risk of seizure recurrence in the 2 years subsequent to the first seizure (Level B), it may not improve the quality of life (Level C).

- Clinicians should advise patients that over the longer term ( $>3$ years), immediate AED treatment is unlikely to improve the prognosis for sustained seizure remission (Level B).

- Patients should be advised that their risk for adverse effects with the use of AEDs ranges from 7 to $31 \%$ (Level B), and that these adverse effects are predominantly mild and reversible. 
each patient. Randomized controlled studies are urgently needed to guide the best clinical decision regarding seizures and epilepsy following SAH.

Conflict of Interests

The authors have no conflicts of interests to declare.

\section{References}

1 Tidswell P, Dias PS, Sagar HJ, Mayes AR, Battersby RD. Cognitive outcome after aneurysm rupture: relationship to aneurysm site and perioperative complications. Neurology 1995;45(05):875-882

2 Stegmayr B, Eriksson M, Asplund K. Declining mortality from subarachnoid hemorrhage: changes in incidence and case fatality from 1985 through 2000. Stroke 2004;35(09):2059-2063

3 Ingall TJ, Whisnant JP, Wiebers DO, O'Fallon WM. Has there been a decline in subarachnoid hemorrhage mortality? Stroke 1989;20 (06):718-724

4 van Gijn J, Rinkel GJ. Subarachnoid haemorrhage: diagnosis, causes and management. Brain 2001;124(Pt 2):249-278

5 Truelsen T, Bonita R, Duncan J, Anderson NE, Mee E. Changes in subarachnoid hemorrhage mortality, incidence, and case fatality in New Zealand between 1981-1983 and 1991-1993. Stroke 1998; 29(11):2298-2303

6 Al-Khindi T, Macdonald RL, Schweizer TA. Cognitive and functional outcome after aneurysmal subarachnoid hemorrhage. Stroke 2010;41(08):e519-e536

7 Buczacki SJ, Kirkpatrick PJ, Seeley HM, Hutchinson PJ. Late epilepsy following open surgery for aneurysmal subarachnoid haemorrhage. J Neurol Neurosurg Psychiatry 2004;75(11):1620-1622

8 Rhoney DH, Tipps LB, Murry KR, Basham MC, Michael DB, Coplin WM. Anticonvulsant prophylaxis and timing of seizures after aneurysmal subarachnoid hemorrhage. Neurology 2000;55(02):258-265

9 Lin C-L, Dumont AS, Lieu A-S, et al. Characterization of perioperative seizures and epilepsy following aneurysmal subarachnoid hemorrhage. J Neurosurg 2003;99(06):978-985

10 Choi KS, Chun HJ, Yi HJ, Ko Y, Kim YS, Kim JM. Seizures and Epilepsy following Aneurysmal Subarachnoid Hemorrhage : Incidence and Risk Factors. J Korean Neurosurg Soc 2009;46(02):93-98

11 Sundaram MB, Chow F. Seizures associated with spontaneous subarachnoid hemorrhage. Can J Neurol Sci 1986;13(03):229-231

12 Hart RG, Byer JA, Slaughter JR, Hewett JE, Easton JD. Occurrence and implications of seizures in subarachnoid hemorrhage due to ruptured intracranial aneurysms. Neurosurgery 1981;8(04):417-421

13 Gilmore E, Choi HA, Hirsch LJ, Claassen J. Seizures and CNS hemorrhage: spontaneous intracerebral and aneurysmal subarachnoid hemorrhage. Neurologist 2010;16(03):165-175

14 Butzkueven H, Evans AH, Pitman A, et al. Onset seizures independently predict poor outcome after subarachnoid hemorrhage. Neurology 2000;55(09):1315-1320

15 Little AS, Kerrigan JF, McDougall CG, et al. Nonconvulsive status epilepticus in patients suffering spontaneous subarachnoid hemorrhage. J Neurosurg 2007;106(05):805-811

16 Lindgren C, Nordh E, Naredi S, Olivecrona M. Frequency of nonconvulsive seizures and non-convulsive status epilepticus in subarachnoid hemorrhage patients in need of controlled ventilation and sedation. Neurocrit Care 2012;17(03):367-373

17 Ohman J. Hypertension as a risk factor for epilepsy after aneurysmal subarachnoid hemorrhage and surgery. Neurosurgery 1990;27 (04):578-581

18 Claassen J, Peery S, Kreiter KT, et al. Predictors and clinical impact of epilepsy after subarachnoid hemorrhage. Neurology 2003;60 (02):208-214

19 Giroud M, Gras P, Fayolle H, André N, Soichot P, Dumas R. Early seizures after acute stroke: a study of 1,640 cases. Epilepsia 1994; 35(05):959-964
20 Hasan D, Schonck RSM, Avezaat CJJ, Tanghe HLJ, van Gijn J, van der Lugt PJ. Epileptic seizures after subarachnoid hemorrhage. Ann Neurol 1993;33(03):286-291

21 Ukkola V, Heikkinen ER. Epilepsy after operative treatment of ruptured cerebral aneurysms. Acta Neurochir (Wien) 1990;106 (3-4):115-118

22 Keränen T, Tapaninaho A, Hernesniemi J, Vapalahti M. Late epilepsy after aneurysm operations. Neurosurgery 1985;17 (06):897-900

23 Olafsson E, Gudmundsson G, Hauser WA. Risk of epilepsy in longterm survivors of surgery for aneurysmal subarachnoid hemorrhage: a population-based study in Iceland. Epilepsia 2000;41 (09):1201-1205

24 Bidziński J, Marchel A, Sherif A. Risk of epilepsy after aneurysm operations. Acta Neurochir (Wien) 1992;119(1-4):49-52

25 Kotila M, Waltimo O. Epilepsy after stroke. Epilepsia 1992;33(03): 495-498

26 Cabral NL, Gonçalves AR, Longo AL, et al. Incidence of stroke subtypes, prognosis and prevalence of risk factors in Joinville, Brazil: a 2 year community based study. J Neurol Neurosurg Psychiatry 2009;80(07):755-761

27 Matthew E, Sherwin AL, Welner SA, Odusote K, Stratford JG. Seizures following intracranial surgery: incidence in the first post-operative week. Can J Neurol Sci 1980;7(04):285-290

28 Kvam DA, Loftus CM, Copeland B, Quest DO. Seizures during the immediate postoperative period. Neurosurgery 1983;12(01):14-17

29 Raper DMS, Starke RM, Komotar RJ, Allan R, Connolly ES Jr. Seizures after aneurysmal subarachnoid hemorrhage: a systematic review of outcomes. World Neurosurg 2013;79(5-6): 682-690

30 Dennis LJ, Claassen J, Hirsch LJ, Emerson RG, Connolly ES, Mayer SA. Nonconvulsive status epilepticus after subarachnoid hemorrhage. Neurosurgery 2002;51(05):1136-1143, discussion 1144

31 Fisher RS, Acevedo C, Arzimanoglou A, et al. ILAE official report: a practical clinical definition of epilepsy. Epilepsia 2014;55(04): 475-482

32 Connolly ES Jr, Rabinstein AA, Carhuapoma JR, et al; American Heart Association Stroke Council; Council on Cardiovascular Radiology and Intervention; Council on Cardiovascular Nursing; Council on Cardiovascular Surgery and Anesthesia; Council on Clinical Cardiology. Guidelines for the management of aneurysmal subarachnoid hemorrhage: a guideline for healthcare professionals from the American Heart Association/american Stroke Association. Stroke 2012;43(06):1711-1737

33 Diringer MN, Bleck TP, Claude Hemphill J III, et al; Neurocritical Care Society. Critical care management of patients following aneurysmal subarachnoid hemorrhage: recommendations from the Neurocritical Care Society's Multidisciplinary Consensus Conference. Neurocrit Care 2011;15(02):211-240

34 Molyneux AJ, Kerr RSC, Yu L-M, et al; International Subarachnoid Aneurysm Trial (ISAT) Collaborative Group. International subarachnoid aneurysm trial (ISAT) of neurosurgical clipping versus endovascular coiling in 2143 patients with ruptured intracranial aneurysms: a randomised comparison of effects on survival, dependency, seizures, rebleeding, subgroups, and aneurysm occlusion. Lancet 2005;366(9488):809-817

35 Raper DMS, Kokabi N, McGee-Collett M. The efficacy of antiepileptic drug prophylaxis in the prevention of early and late seizures following repair of intracranial aneurysms. J Clin Neurosci 2011; 18(09):1174-1179

36 Johansson M, Cesarini KG, Contant CF, Persson L, Enblad P. Changes in intervention and outcome in elderly patients with subarachnoid hemorrhage. Stroke 2001;32(12):2845-2949

37 Scott RB, Eccles F, Molyneux AJ, Kerr RSC, Rothwell PM, Carpenter K. Improved cognitive outcomes with endovascular coiling of ruptured intracranial aneurysms: neuropsychological outcomes from the International Subarachnoid Aneurysm Trial (ISAT). Stroke 2010;41(08):1743-1747(ISAT) 
38 Hesdorffer DC, Benn EKT, Cascino GD, Hauser WA. Is a first acute symptomatic seizure epilepsy? Mortality and risk for recurrent seizure. Epilepsia 2009;50(05):1102-1108

39 Marigold R, Günther A, Tiwari D, Kwan J. Antiepileptic drugs for the primary and secondary prevention of seizures after subarachnoid haemorrhage. Cochrane Database Syst Rev 2013;(06): CD008710

40 Sakowitz OW, Raabe A, Vucak D, Kiening KL, Unterberg AW. Contemporary management of aneurysmal subarachnoid hemorrhage in germany: results of a survey among 100 neurosurgical departments. Neurosurgery 2006;58(01):137-145, discussion 137-145

41 Naidech AM, Kreiter KT, Janjua N, et al. Phenytoin exposure is associated with functional and cognitive disability after subarachnoid hemorrhage. Stroke 2005;36(03):583-587

42 Rosengart AJ, Huo JD, Tolentino J, et al. Outcome in patients with subarachnoid hemorrhage treated with antiepileptic drugs. J Neurosurg 2007;107(02):253-260

43 Chumnanvej S, Dunn IF, Kim DH. Three-day phenytoin prophylaxis is adequate after subarachnoid hemorrhage. Neurosurgery 2007;60(01):99-102, discussion 102-103

44 Silverman IE, Restrepo L, Mathews GC. Poststroke seizures. Arch Neurol 2002;59(02):195-201

45 Krumholz A, Wiebe S, Gronseth GS, et al. Evidence-based guideline: Management of an unprovoked first seizure in adults: Report of the Guideline Development Subcommittee of the American Academy of Neurology and the American Epilepsy Society. Neurology 2015;84(16):1705-1713

46 Hauser WA, Rich SS, Lee JR-J, Annegers JF, Anderson VE. Risk of recurrent seizures after two unprovoked seizures. N Engl J Med 1998;338(07):429-434
47 Kim LG, Johnson TL, Marson AG, Chadwick DW; MRC MESS Study group. Prediction of risk of seizure recurrence after a single seizure and early epilepsy: further results from the MESS trial. Lancet Neurol 2006;5(04):317-322

48 French JA, Kanner AM, Bautista J, et al; Therapeutics and Technology Assessment Subcommittee of the American Academy of Neurology; Quality Standards Subcommittee of the American Academy of Neurology; American Epilepsy Society. Efficacy and tolerability of the new antiepileptic drugs I: treatment of new onset epilepsy: report of the Therapeutics and Technology Assessment Subcommittee and Quality Standards Subcommittee of the American Academy of Neurology and the American Epilepsy Society. Neurology 2004;62(08):1252-1260

49 Glauser T, Ben-Menachem E, Bourgeois B, et al; ILAE Subcommission on AED Guidelines. Updated ILAE evidence review of antiepileptic drug efficacy and effectiveness as initial monotherapy for epileptic seizures and syndromes. Epilepsia 2013;54(03):551-563

50 Marson AG, Al-Kharusi AM, Alwaidh M, et al; SANAD Study group. The SANAD study of effectiveness of carbamazepine, gabapentin, lamotrigine, oxcarbazepine, or topiramate for treatment of partial epilepsy: an unblinded randomised controlled trial. Lancet 2007; 369(9566):1000-1015

51 Marson AG, Al-Kharusi AM, Alwaidh M, et al; SANAD Study group. The SANAD study of effectiveness of valproate, lamotrigine, or topiramate for generalised and unclassifiable epilepsy: an unblinded randomised controlled trial. Lancet 2007;369(9566):1016-1026

52 Marson AG, Appleton R, Baker GA, et al. A randomised controlled trial examining the longer-term outcomes of standard versus new antiepileptic drugs. The SANAD trial. Health Technol Assess 2007; 11(37):iii-iv, ix-x, 1-134 